\title{
Fibre distribution in the lungs and pleura of subjects with asbestos related diffuse pleural fibrosis
}

\author{
A R Gibbs, M Stephens, D M Griffiths, B J N Blight, F D Pooley
}

\begin{abstract}
The lungs from 13 cases of diffuse pleural fibrosis associated with a history of exposure to asbestos were examined. Samples were taken from the visceral pleura and central and subpleural zones of the lungs for histopathological and mineralogical studies. The fibre type, size, and number were estimated for each of these regions by transmission electron microscopy and energy dispersive $x$ ray analysis. Amphibole fibre counts were raised when compared with a non-occupationally exposed group and matched those seen in cases of pleural plaques, mild asbestosis, and mesothelioma. A wide case to case variation of distribution was seen. No significant difference was apparent between central and subpleural zones, whereas low asbestos counts were found in the pleura; these were mainly short chrysotile fibres. Within the lungs more $(45 \%)$ of the longer $(>4 \mu \mathrm{m})$ and thinner $(<0.25 \mu \mathrm{m})$ amphibole fibres were retained in keeping with other studies implicating such fibre profiles in the pathogenesis of asbestos related disease.
\end{abstract}

Lungs affected by moderate to severe asbestosis are often also affected by diffuse pleural fibrosis. ${ }^{1}$ Diffuse pleural fibrosis can also occur, however, as the principal lesion due to exposure to asbestos in the

Department of Pathology, Llandough Hospital, Penarth and Environmental Lung Disease Research Group, Llandough Hospital

A R Gibbs

Department of Pathology, City Hospital, Hucknall Road, Nottingham (present address Central Pathology Laboratory, Stoke on Trent)

M Stephens

Department of Mining and Minerals Engineering, University College, Cardiff and Environmental Lung Disease Research Group, Llandough Hospital D M Griffiths

DataStat Consultants, 42 Sterndale Road, London W14 0HU

B J N Blight

School of Engineering, Division of Materials and Minerals, University College, Cardiff and Environmental Lung Disease Research Group, Llandough Hospital

F D Pooley absence of significant parenchymal disease. ${ }^{2}$ We have previously presented the macroscopic, microscopical, and mineralogical findings of seven cases of diffuse pleural fibrosis ${ }^{3}$ and some preliminary information on mineral fibre distribution of a series of 13 cases. ${ }^{4}$ Now we have investigated the type and size distributions of mineral fibres at different sites within the lung and visceral pleura.

\section{Methods}

Lungs obtained at 13 postmortem examinations performed between 1979 and 1988 were studied. They were from either routine hospital necropsies or from cases referred by the Medical Boarding Centre. Occupational histories were obtioined from either the hospital notes or from the Medical Boarding Centre. Seven of the cases formed the basis of our original study. ${ }^{3}$

Cases were selected using diagnostic criteria acceptable for compensatory asbestos induced disease $^{2}$ and similar to those identified previously. ${ }^{3}$ These consisted of the necropsy findings of bilateral diffuse pleural fibrosis covering more than $25 \%$ of the lung surface on each side and measuring more than $5 \mathrm{~mm}$ in thickness at some point, in conjunction with documented exposure to asbestos.

\section{TISSUE PREPARATION}

At least one lung from each case was distended with formalin in the standard manner and examined microscopically after fixation. Tissue blocks for histology were taken from the following sites:

(1) Subpleural region of the apex of upper lobe.

(2) Subpleural region of the apex of lower lobe.

(3) Subpleural region of the base of lower lobe.

(4) Central region of upper lobe.

(5) Central region of lower lobe.

(6) Pleural fibrosis-multiple blocks.

Tissue for mineralogical analysis was sampled as detailed in the next section.

The formalin fixed and paraffin embedded blocks were processed in the standard manner and the sections prepared were stained with haematoxylin and eosin, Martius scarlet blue (for fibrous tissue), and elastic van Gieson stain (for elastic and fibrous tissue). The degree of parenchymal fibrosis was graded $0-\mathbf{4}$ for each slide using an established system and an average was obtained for each case. ${ }^{56}$ 
Table 1 Ages, occupational histories, and histological grades of fibrosis in the 13 cases of diffuse pleural fibrosis with a history of exposure to asbestos

\begin{tabular}{llll}
\hline Subject & Age $(y)$ & Occupational history & Grade of fibrosis \\
\hline 1 & 80 & Pipe fitter for 25 years & 2 \\
2 & 67 & Engineer, two years cutting asbestos sheets & $2 / 3$ \\
3 & 64 & Boiler maker & $1 / 2$ \\
4 & 75 & Electrical welder & 2 \\
5 & 71 & Carpenter, cutting roofing sheets & $1 / 2$ \\
6 & 64 & Asbestos sprayer & $2 / 3$ \\
7 & 62 & Uniler lagger, 33 years exposure & 1 \\
8 & 64 & Production osbestos sacks (four years) & 2 \\
9 & 47 & Mixing/moulding blue asbestos for one year & $0 / 1$ \\
10 & 69 & Marine engine fitter for 35 years & N/D \\
11 & 54 & Gas fitter and plumber for “a few years" & $0 / 1$ \\
12 & 75 & Refitting ships for 25 years & 1 \\
13 & 74 & Shipyard joiner & $2 / 3$ \\
\hline
\end{tabular}

\section{MINERAL FIBRE ANALYSIS}

Material for mineralogical analysis was obtained from tissues removed from the parenchyma immediately adjacent to the blocks (1)-(6) taken for histology as listed. The analysis for the subpleural region was performed by pooling samples adjacent to blocks (1)-(3), for the central region by pooling samples adjacent to (4) and (5), and pleural fibrosis by pooling samples adjacent to blocks from (6).

Counting, typing, and sizing were undertaken as a standard procedure previously reported for our laboratory. ${ }^{7}$ Briefly, tissue samples were divided into two. One half was dried at $80^{\circ} \mathrm{C}$ and the wet to dry weight calculated. The other was digested in $40 \%$ potassium hydroxide, washed, and then ashed at $350^{\circ} \mathrm{C}$ for three hours in an atmosphere of oxygen. The final extract was suspended in distilled water and aliquots of known volume were filtered on to nucleopore filters. These were carbon coated, the filters were dissolved in chloroform, and the carbon films were mounted on to gold electron microscope support grids for transmission electron microscopy. At least 200 fibres were counted and each one was typed by an energy dispersive $x$ ray analysis technique. The length and width of 100 to 200 fibres were also determined at this time.

\section{Results}

Table 1 gives the occupational details of each patient. All were men and the age of death ranged from 47 to 80 years. Duration of exposure to asbestos varied from one to 35 years. Pathological examination showed changes similar to those described previously by us. ${ }^{3}$ In all cases macroscopic examination showed extensive diffuse visceral pleural fibrosis that was at least $5 \mathrm{~mm}$ in thickness but reached $4 \mathrm{~cm}$ in thickness. This mimicked pleural mesothelioma in some cases. Several cases had extensive adhesions between the visceral and parietal pleura. In some, recognisable pleural plaques were also present. Case 10 showed severe diffuse pericardial fibrosis similar to that of the pleura. Microscopically the pleura showed mature collagen arranged in a basket weave pattern. Table 1 gives the degree of pulmonary parenchymal fibrosis graded for each case.

Table 2 Asbestos fibre counts for each case in subpleural (S), central (C), and pleural (P) sites

\begin{tabular}{|c|c|c|c|c|c|c|c|c|c|c|c|c|}
\hline \multirow[b]{2}{*}{ Subject } & \multicolumn{3}{|c|}{ Total asbestos } & \multicolumn{3}{|c|}{ Crocidolite } & \multicolumn{3}{|c|}{ Amosite } & \multicolumn{3}{|c|}{ Chrysotile } \\
\hline & $\boldsymbol{S}$ & $C$ & $P$ & $\boldsymbol{S}$ & $C$ & $P$ & $S$ & $C$ & $P$ & $S$ & $C$ & $P$ \\
\hline $\begin{array}{r}1 \\
2 \\
3 \\
4 \\
5 \\
6 \\
7 \\
8 \\
9 \\
10 \\
11 \\
12 \\
13\end{array}$ & $\begin{array}{c}21 \cdot 5 \\
12 \cdot 8 \\
8 \cdot 7 \\
16 \cdot 7 \\
3 \cdot 28 \\
327 \cdot 22 \\
99 \cdot 4 \\
165 \cdot 8 \\
24 \cdot 6 \\
60 \cdot 9 \\
8 \cdot 53 \\
158 \cdot 4 \\
31 \cdot 2\end{array}$ & $\begin{array}{c}7 \cdot 2 \\
5.6 \\
13.9 \\
13.2 \\
6.22 \\
247.69 \\
123.0 \\
131.5 \\
11.0 \\
14.9 \\
12.9 \\
92.4 \\
22.6\end{array}$ & $\begin{array}{c}1.96 \\
6.6 \\
6 \cdot 2 \\
14 \cdot 7 \\
2 \cdot 11 \\
119 \\
10 \cdot 1 \\
10.8 \\
2.5 \\
16.4 \\
3.3 \\
2 \cdot 1 \\
13.2\end{array}$ & $\begin{array}{c}2.1 \\
9.6 \\
1.7 \\
7.7 \\
0.5 \\
305.95 \\
13.2 \\
10.3 \\
3.4 \\
5.3 \\
0.05 \\
66.7 \\
0.05\end{array}$ & $\begin{array}{c}1.0 \\
2.7 \\
1.4 \\
5.5 \\
0.78 \\
228.12 \\
27.6 \\
13.7 \\
1.6 \\
1.9 \\
0.35 \\
31.4 \\
0.45\end{array}$ & $\begin{array}{c}0.04 \\
0.5 \\
0.05 \\
0.04 \\
0.19 \\
85.0 \\
0.9 \\
0.2 \\
0.04 \\
0.04 \\
0.05 \\
0.1 \\
0.5\end{array}$ & $\begin{array}{r}5 \cdot 8 \\
0 \cdot 8 \\
1 \cdot 2 \\
2 \cdot 1 \\
1 \cdot 7 \\
160 \cdot 3 \\
78 \cdot 4 \\
117 \cdot 3 \\
1 \cdot 2 \\
33 \cdot 6 \\
0 \cdot 1 \\
75 \cdot 2 \\
0.6\end{array}$ & $\begin{array}{c}3.9 \\
1.0 \\
1.0 \\
1.6 \\
1.98 \\
195.6 \\
86.0 \\
81.7 \\
0.7 \\
10.4 \\
0.35 \\
51.7 \\
0.45\end{array}$ & $\begin{array}{c}0.01 \\
0.01 \\
0.19 \\
0.01 \\
0.01 \\
12.8 \\
0.01 \\
0.9 \\
0.01 \\
0.3 \\
0.01 \\
0.1 \\
0.01\end{array}$ & $\begin{array}{c}13 \cdot 2 \\
2 \cdot 1 \\
5 \cdot 8 \\
6 \cdot 6 \\
1 \cdot 1 \\
523 \\
7 \cdot 0 \\
25 \cdot 7 \\
19 \cdot 7 \\
22 \cdot 0 \\
8 \cdot 43 \\
16 \cdot 5 \\
30 \cdot 6\end{array}$ & $\begin{array}{c}2 \cdot 2 \\
1 \cdot 8 \\
11 \cdot 3 \\
5 \cdot 9 \\
3 \cdot 46 \\
0 \cdot 18 \\
8 \cdot 6 \\
32 \cdot 2 \\
8 \cdot 7 \\
2 \cdot 6 \\
12 \cdot 2 \\
9 \cdot 3 \\
21 \cdot 7\end{array}$ & $\begin{array}{c}1.92 \\
6 \cdot 0 \\
5 \cdot 95 \\
14 \cdot 0 \\
1.92 \\
20.9 \\
9 \cdot 2 \\
10 \cdot 4 \\
2.5 \\
16 \cdot 1 \\
3 \cdot 25 \\
1.8 \\
12.7\end{array}$ \\
\hline
\end{tabular}

Values are $\times 10^{6} / \mathrm{g}$ dried lung tissue. 
Table 3 Counts for fibres from all cases (except 6) classified by fibre type and position

\begin{tabular}{llccr}
\hline & Amosite $\left(\times 10^{6}\right.$ fibres $\left./ g\right)$ & Crocidolite $\left(\times 10^{6}\right.$ fibres $\left./ \mathrm{g}\right)$ & Chrysotile $\left(\times 10^{6}\right.$ fibres $\left./ \mathrm{g}\right)$ & All $\left(\times 10^{6}\right.$ fibres $\left./ \mathrm{g}\right)$ \\
\hline Subpleural & 330.89 & 120.85 & 158.72 & 610.46 \\
Central & 242.38 & 87.69 & 127.24 & 457.31 \\
Pleural & 0.39 & 2.53 & 86.68 & 89.60 \\
All & 573.66 & 211.07 & 372.64 & 1157.36 \\
\hline
\end{tabular}

Table 2 gives the total and specific fibre counts for each case for the different anatomical sites. Considerable case to case variations occurred in fibre distribution. Case 6 had extreme values and is treated as an outlier. Therefore, the figures apply to all dusts with the omission of case 6 .

Table 3 gives the counts for the various asbestos fibres at different anatomical sites. The pleura contained much lower concentrations of amphibole than chrysotile fibres. The chrysotile fibre concentrations showed less variability over the different sites.

Tables 4 and 5 show the geometric means of the fibre widths and lengths together with the standard deviations of the log widths and log lengths These particular statistics are appropriate due to the tendency for fibre dimensions to be distributed as log normals. This assumption was supported by the data on length but not so much by those on width.

The effects of fibre type and position were investigated by a two way weighted analysis of variance (weighted by counts) using type and position as factors, each at three levels. The analysis of variance is a standard statistical technique for data in which variability can be partly explained by two factors-in this case fibre type and fibre position. Due to the disparity in fibre counts it is appropriate to weight the analysis by sample size. No interactions were found between the factors although definite differences due to type and position occurred.

Table 6 shows the analysis of variance. The fibre effect was significant for both width and length $(p<0.0001)$. Position was significant for lengths (p $<0.02)$ but not for widths.

Further analysis of these effects showed the following differences, apparent from tables 4 and 5 . The amosite fibres were longer $(p<0.025)$ and wider $(p<0.0001)$ than the crocidolite, which were longer

Table 4 Geometric mean ( $S D$ of log) widths ( $\mu m$ ) of fibres

\begin{tabular}{lllll}
\hline & Amosite & Crocidolite & Chrysotile & All \\
\hline Subpleural & $0.17(0.80)$ & $0.10(0.63)$ & $0.06(0.13)$ & $0.12(0.78)$ \\
Central & $0.17(0.73)$ & $0.09(0.61)$ & $0.07(0.22)$ & $0.12(0.73)$ \\
Pleural & $0.17(0.79)$ & $0.08(0.45)$ & $0.06(0.17)$ & $0.06(0.21)$ \\
All & $0.17(0.77)$ & $0.10(0.62)$ & $0.06(0.18)$ & $0.11(0.75)$ \\
\hline
\end{tabular}

Table 5 Geometric mean (SD of log) lengths ( $\mu m$ ) of fibres

\begin{tabular}{lllll}
\hline & Amosite & Crocidolite & Chrysotile & All \\
\hline Subpleural & $3.68(0.82)$ & $3.17(0.88)$ & $1.39(0.89)$ & $2.77(0.94)$ \\
Central & $3.63(0.87)$ & $3.07(0.83)$ & $1.32(0.89)$ & $2.65(0.97)$ \\
Pleural & $1.23(0.82)$ & $2.30(0.94)$ & $0.96(0.79)$ & $0.99(0.80)$ \\
All & $3.66(0.84)$ & $3.12(0.86)$ & $1.25(0.88)$ & $2.52(0.98)$ \\
\hline
\end{tabular}

( $p<0.0001)$ and wider $(p<0.0001)$ than the chrysotile. No differences in fibre dimensions were seen between the central and subpleural parenchymal sites but the pleural fibres were generally shorter $(p<0.05)$ than those in the parenchyma.

Figures 1 to 3 show the percentage of specific fibres measured in each length category for different fibre widths. The percentage of long amphibole fibres found in the lung was clearly higher than that for chrysotile fibres. Furthermore, a significant percentage of these were both long and thin.

Table 7 gives the mean and range of fibre counts for several types of asbestos fibres in non-occupationally exposed subjects (unpublished data). This indicates the low concentrations of amphibole in the general population.

\section{Discussion}

This study expands upon our original paper on asbestos induced diffuse pleural fibrosis ${ }^{3}$ and adds new

Table 6 Analysis of variance of log lengths and widths of asbestos fibres

\begin{tabular}{lcccr}
\hline Factor & $\begin{array}{l}\text { Degrees of } \\
\text { freedom }\end{array}$ & $\begin{array}{l}\text { Sums of } \\
\text { squares }\end{array}$ & $\begin{array}{l}\text { Mean } \\
\text { square }\end{array}$ & F Value \\
\hline \multicolumn{5}{c}{ Analysis of variance of log lengths } \\
Position & 2 & 8.51 & 4.255 & 4.53 \\
Fibre & 2 & 194.2 & 97.1 & 103.27 \\
Interaction & 4 & 0.3 & 0.075 & 0.08 \\
Residual & 893 & 839.65 & 0.94 & \\
Total & 901 & 1119.6 & & \\
& \multicolumn{4}{c}{} \\
Position & Analysis of variance of log widths & \\
Fibre & 2 & 0.03 & 0.015 & 0.03 \\
Interaction & 2 & 186.2 & 93.1 & 191.19 \\
Residual & 4 & 0.28 & 0.07 & 0.14 \\
Total & 893 & 434.84 & 0.49 & \\
& 901 & 649.99 & & \\
\hline
\end{tabular}



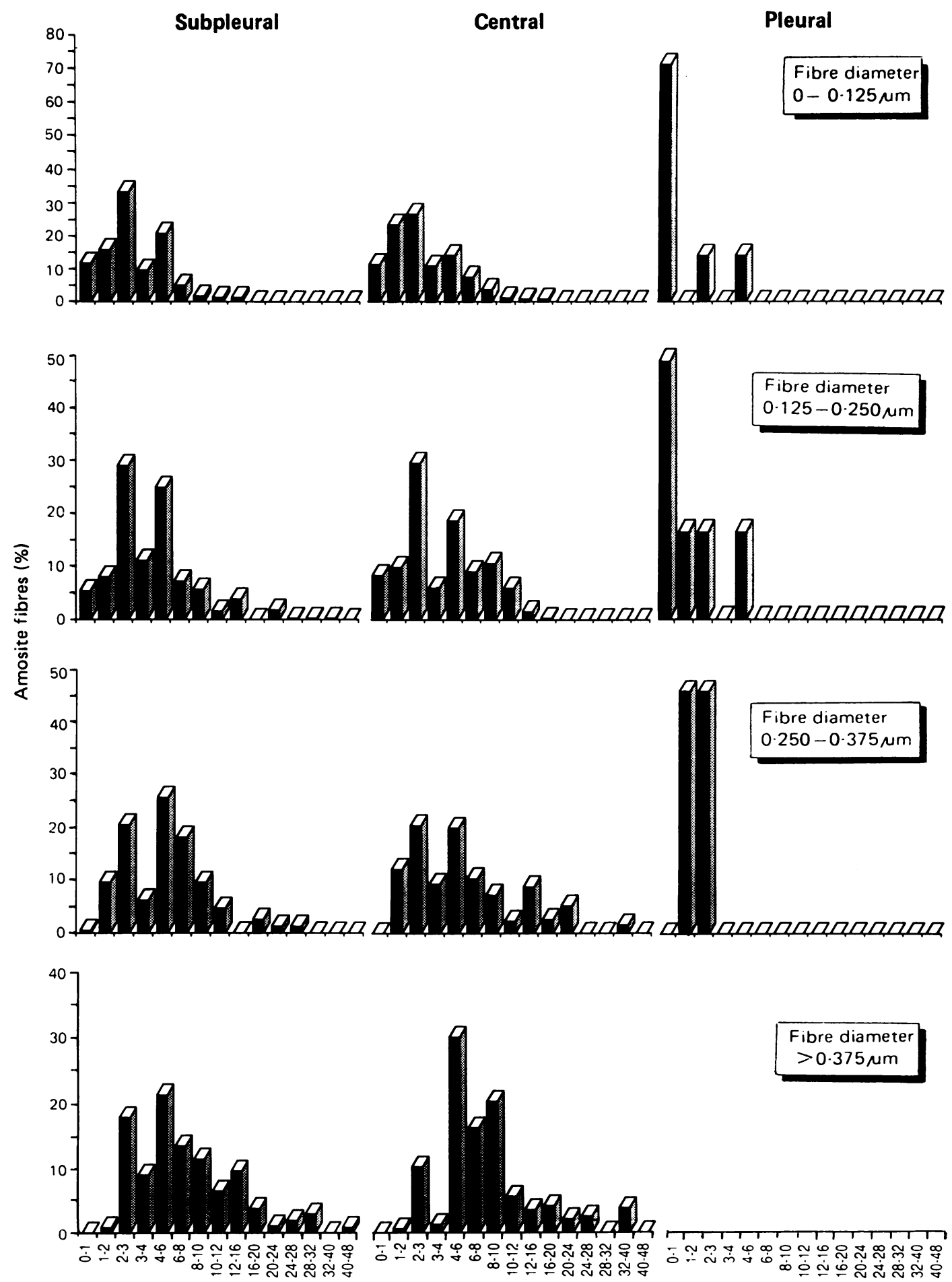

Fibre length ( $\mu \mathrm{m})$

Figure 1 Fibre length distribution for amosite. 


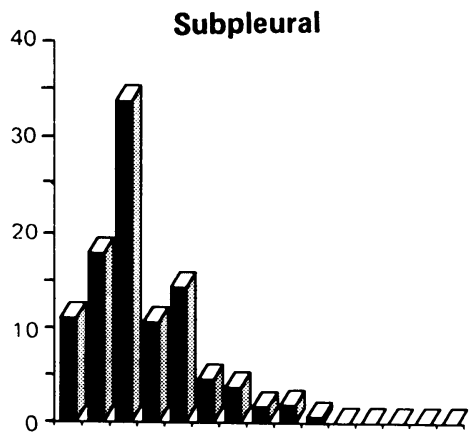

Central
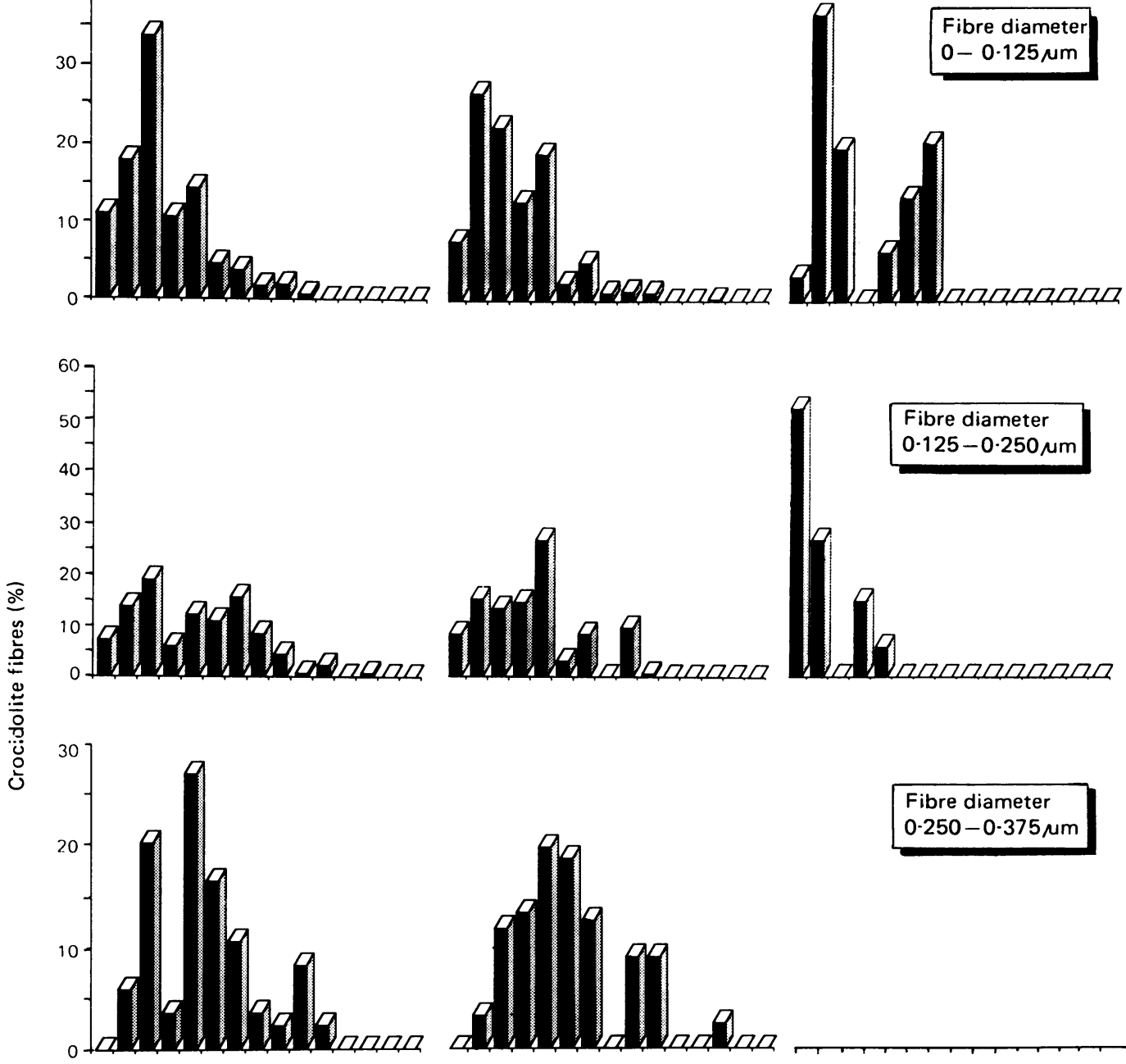

Fibre diameter $0.250-0.375 \mu \mathrm{m}$

Fibre diameter $>0.375 \mu \mathrm{m}$

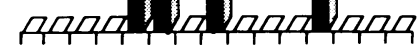
-

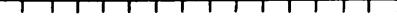

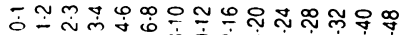
- N 

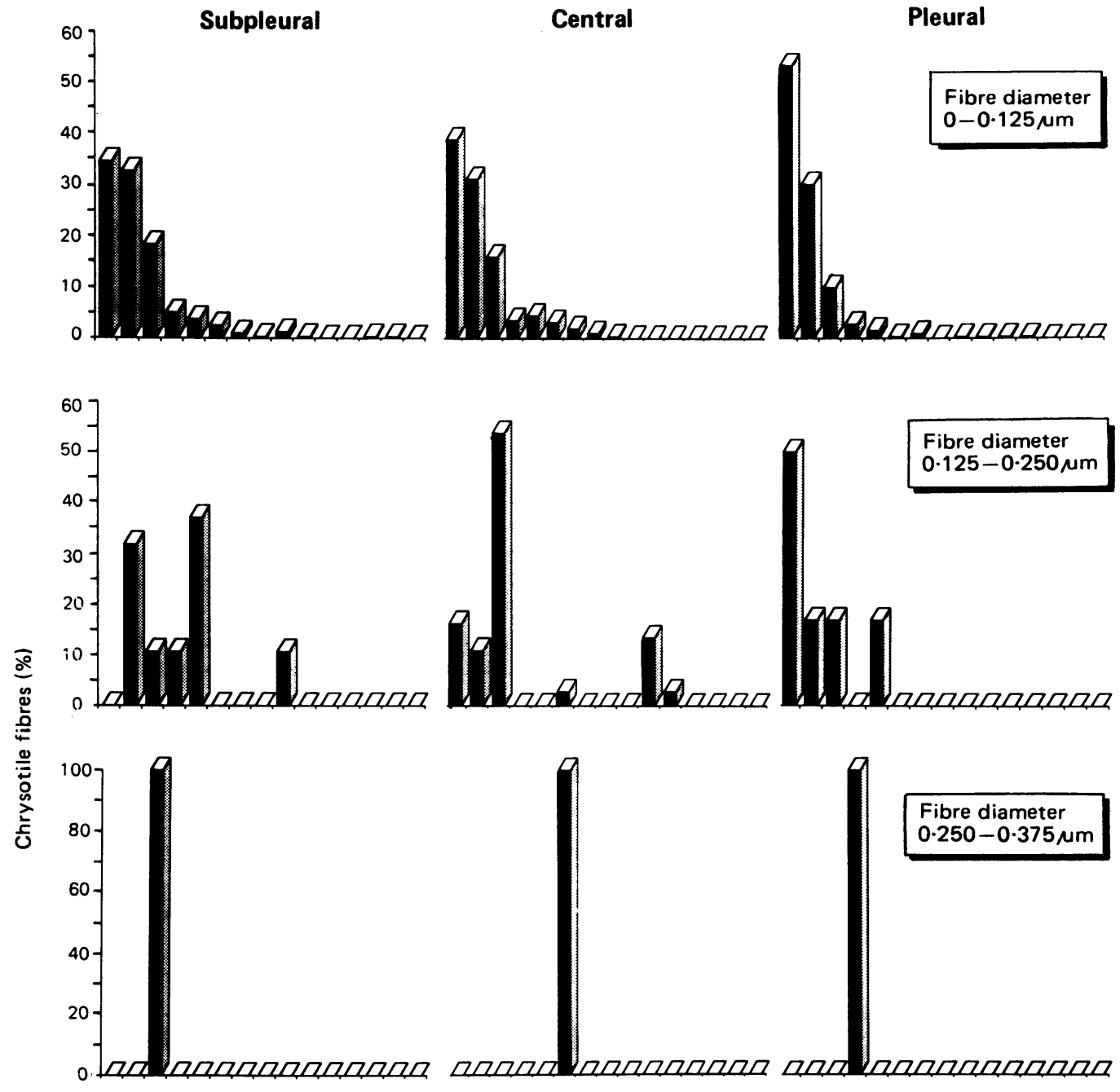

Fibre diameter $0.125-0.250 \mathrm{um}$
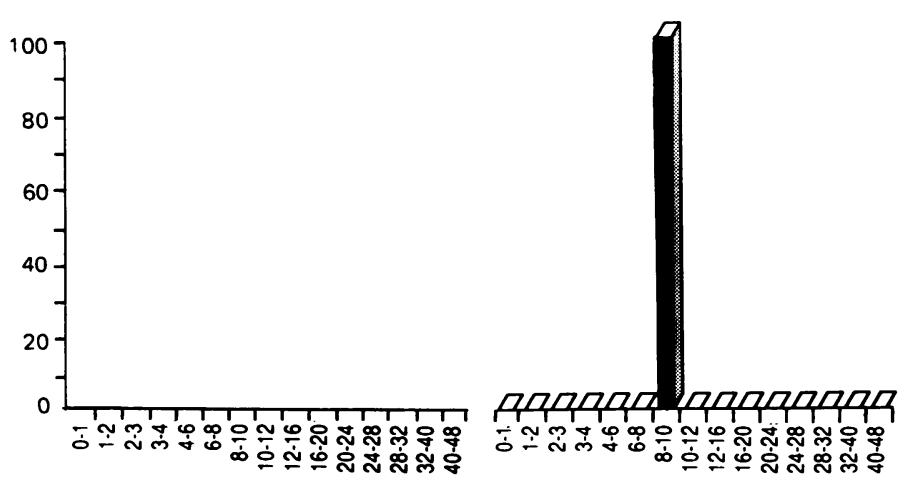

Fibre diameter $0.250-0.375 \mathrm{um}$

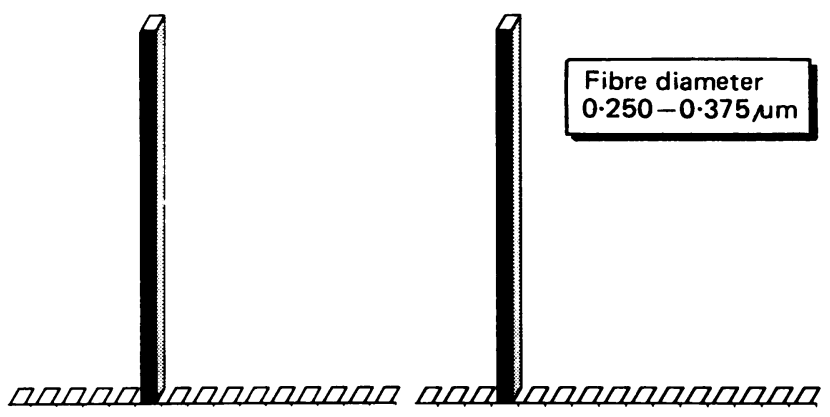

Fibre length ( $\mathrm{Mm}$ )

Figure 3 Fibre length distribution for chrysotile.

Fibre diameter $>0.375 \mu \mathrm{m}$

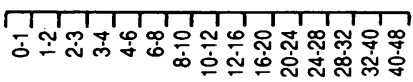


Table 7 Average counts for 55 Cardiff controls by electron microscopy

\begin{tabular}{llll}
\hline & $\begin{array}{l}\text { Arithmetic } \\
\text { mean }\end{array}$ & $\begin{array}{l}\text { Geometric } \\
\text { mean }\end{array}$ & Range of counts \\
\hline Chrysotile & 2.8 & 1.4 & 0 to 11.7 \\
Amosite & 0.09 & 0.02 & 0 to 1.0 \\
Crocidolite & 0.14 & 0.02 & 0 to 1.7 \\
Tremolite & 0.02 & 0.01 & 0 to 0.4 \\
Mullite & 11.6 & 5.2 & 0 to 78.0 \\
Total & 15.6 & 9.5 & 0.3 to 83.1 \\
\hline
\end{tabular}

Values are $\times 10^{6} / \mathrm{g}$ dried lung tissue.

information on fibre load, distribution, and size. The present cases were designated as representing diffuse pleural fibrosis on morphological grounds by the previously defined criteria including severe diffuse fibrosis of the pleura, mild parenchymal fibrosis, and documented exposure to asbestos. Of the cases presented here all had had occupational exposure to asbestos but in our opinion the findings were likely to have been caused by the asbestos in only 11 . Subject 13 had been treated for pulmonary tuberculosis nine months before death. Examination of multiple histological sections showed a few caseating granulomas. The lung showed severe fibrosis but very low asbestos counts, well within the range of our normal controls; therefore, tuberculosis was most probably the cause of the pleural fibrosis in this case. Subject 11 had a vague history of exposure to asbestos and lung asbestos counts well within our normal nonoccupationally exposed level (table 7). The cause of the fibrosis in this case was unknown but was considered unlikely to be due to asbestos. These two cases underline the necessity to obtain accurate asbestos counts; without these an asbestos related aetiology cannot be proved as other causes of diffuse pleural fibrosis exist. ${ }^{8}$ The clinical data available in these cases were not detailed enough to make an assessment of any specific recognisable biological factor increasing susceptibility to this type of pleural reaction. It has been suggested that immunological factors may be important. ${ }^{9-11}$

Examination of our own unpublished observations (table 7) and reference to previous data ${ }^{12-14}$ indicated that the total asbestos counts in these 11 cases of diffuse pleural fibrosis were generally higher than those found in the non-occupationally exposed population. This observation applied to the amphibole rather than the chrysotile concentrations. The concentrations found appear to correspond with those seen in cases with pleural plaques, ${ }^{1315}$ mild asbestosis ${ }^{16}$ and mesothelioma. These findings accord with those of other authors who also find that asbestos related disease is associated more closely with amphibole lung content than with chryso- tile. ${ }^{16-19}$ The concentrations of asbestos found clearly implicate this mineral in the pathogenesis of diffuse pleural fibrosis but do not provide any indication as to what produces this particular reaction rather than any other pathological reaction.

The pleura contained little fibre, most of which was chrysotile; only occasional amphibole fibres were detected. Total subpleural asbestos concentrations were not significantly increased compared with central lung fibre concentrations. An appreciable case to case variation of fibre distribution was seen. This non-uniform fibre distribution, including variation of fibre concentrations in various parts of the lung, the paradoxical paucity of fibres in the pleura, and the predominance of chrysotile at this site, is a recurring finding in studies of different asbestos related diseases. ${ }^{20-24}$

The sizing data are of interest. The length and width of amosite in general exceeds that of crocidolite, which exceeds that of chrysotile. No difference occurred for fibre dimensions between the subpleural and central sites. This finding is at variance with the limited data available on fibre size distribution in other asbestos related diseases. ${ }^{23}$ The relevance of this is uncertain at present but it could reflect either a true difference between disease states, a different method of sampling, processing, and analysis, or merely reflect the fact that a general pattern has not emerged due to the paucity of information available.

A high percentage of retained amphibole fibres were long $(9 \%$ of amphiboles were greater than $10 \mu \mathrm{m}$ in length and $45 \%$ were greater than $4 \mu \mathrm{m}$ in length compared with chrysotile fibres for which the values were $2 \%$ and $9 \%$ respectively; figs $1-3$ ). Furthermore, as far as thin fibres (less than $0.25 \mu \mathrm{m}$ in diameter) were concerned, $37 \%$ of the amphiboles were greater than $4 \mu \mathrm{m}$ in length compared with $9 \%$ of chrysotile fibres (fig 2). The pleura, as well as containing minimal numbers of amphibole fibres, contained predominantly short chrysotile fibres (tables 3 and 5). These findings are in keeping with previous studies on other asbestos related diseases, which find a high percentage of both long and thin fibres in the lung parenchyma and minimal numbers of short fibres in the pleura ${ }^{20}$ It has been noted that fibres greater than $8 \mu \mathrm{m}$ in length have an increased fibrogenic and oncogenic potential, although many consider fibres greater than $5 \mu \mathrm{m}$ in length are those of major pathogenic importance. ${ }^{24} 25$

Several observations have been made that explain these findings. Morphologically, chrysotile fibres are curled and act as three dimensional objects with random alignment in the airways, causing increased deposition at airway bifurcations $\mathrm{s}^{26-29}$ and consequent increased ciliary clearance. By contrast, amphibole fibres are straight, essentially one dimensional, and align with the airstream in the airways allowing 
deeper penetration than the curled fibres. ${ }^{26-29}$ The alveolar deposition of fibres also lessens steeply with diameters greater than $2-3 \mu \mathrm{m}$ leading to selective deposition of relatively thin fibres. Short asbestos fibres $(<5 \mu \mathrm{m})$ are cleared more effectively than long fibres, ${ }^{3031}$ giving rise to the idea that the longer fibres bridge alveolar ducts and penetrate the alveolar walls. It has been suggested that chrysotile fibres have a greater tendency to fragment with time in the lung resulting in a continual clearance, decrease in the load, and a relative increase in the population of smaller fibres, but the evidence for this is conflicting. These comments are obviously of direct relevance in necropsy studies, when the lung content will more accurately reflect the retained fibres rather than the total lifetime exposure. Some authors such as Pooley and Wagner ${ }^{19}$ have suggested that the selectively retained longer and thinner amphibole fibres are of prime pathogenetic importance. Other workers have, however, warned that the low concentrations of relatively short (largely chrysotile) fibres do not necessarily indicate a low level of pathogenicity ${ }^{31}$; it being difficult to exclude a "hit and run" effect. Epidemiological studies, however, implicate amphiboles as being more important in pathogenicity. ${ }^{32-34}$

It is becoming increasingly obvious that as well as the importance of concentrations of the specific fibre types in the lung in the various asbestos related diseases, fibre dimension profiles are of significance. There is a paucity of data on the detailed analysis of fibre type dimension in the various disease states and the exact relation of fibre dimension to particular pathological effects will have to await further experimental and comparative work in human subjects. This knowledge may be of paramount importance in the prevention of similar disease states induced by other man made mineral fibres when one considers the fact that fibre dimension often appears to be of greater importance than the specific fibre chemistry.

In conclusion, this study has documented detailed mineralogical data in asbestos related diffuse pleural fibrosis. We have confirmed that amphiboles rather than chrysotile fibres are retained in the lung and that a high percentage of these are long and thin. We have also confirmed the non-uniform distribution of asbestos fibres in the lung, in particular a low fibre content in pleural tissue, most of which is chrysotile.

Our thanks are due to Professor Stephen Jones and Dr P Smith (Nottingham) for allowing us to study their cases and also to Mr D Llewellyn for the illustrations.

The work was carried out as part of Health and Safety Executive Comission No 1/LMD/126270/88 entitled biological effects of mineral dusts.
1 Wagner JC. Some pathological aspects of asbestosis in the Union of South Africa. In: Orenstein AJ, ed. Proceedings of the pneumoconiosis conference, 1959. Johannesburg: Churchill Livingstone, 1960:373-82.

2 Davis D. Asbestos induced disease without asbestosis. BMJ 1983;287:164-5.

3 Stephens M, Gibbs AR, Pooley FD, Wagner JC. Asbestos induced diffuse pleural fibrosis. Pathology and mineralogy. Thorax 1987;42:583-8.

4 Gibbs AR, Griffiths DM, Stephens M, Pooley FD. Asbestos related diffuse pleural fibrosis. Proceedings of the seventh International pneumoconiosis conference. Pittsburgh: 1988;915-8.

5 Hinson KFW, Otto H, Webster I, Rossiter CE. Criteria for the diagnosis and grading of asbestosis. In: Bogovski P, Gilson JC, Timbrell V, Wagner JC, eds. Biological effects of asbestos. Lyon: International Agency for Research on Cancer, 1973:54-7. (Sci publ No 8.)

6 Craighead JE, Abraham L, Churg A, et al. Asbestos associated diseases. Report of the pneumoconiosis committee of the College of American Pathologists and National Institute for Occupational Safety and Health. Arch Path Lab Med 1982; 106:541-95.

7 Pooley FD, Clark NJ. Quantitative assessment of inorganic fibrous particulates in dust samples with an analytical transmission electron microscope. Ann Occup Hyg 1979;22:253-72.

8 Herbert A. Pathogenesis of pleurisy, pleural fibrosis and mesothelial proliferation. Thorax 1986;41:176-89.

9 Large A. An epidemiological survey of immunological abnormalities in asbestos workers. I Non-organ specific and organ specific autoantibodies. Environ Res 1980;22:162-75.

10 Large A. An epidemiological survey of immunoglobulin abnormalities in asbestos workers. II Serum immunoglobulin levels. Environ Res 1980;22:176-83.

11 Hillerdal G. Pleural changes and exposure to fibrous minerals. Scand $J$ Work Environ Health 1984;10:473-9.

12 Jones JSP, Pooley FD, Clark NJ, et al. The pathology and mineral content of lungs in cases of mesothelioma in the United Kingdom in 1976. In: Wagner JC, ed. Biological effects of mineral fibres. Lyon: International Agency for Research on Cancer, 1980:187-99. (Sci publ No 30.)

13 Churg A. Fibre counting and analysis in the diagnosis of asbestos related disease. Hum Pathol 1982;13:381-92.

14 Churg A, Warnock $M$. Asbestos fibres in the general population. Am Rev Respir Dis 1980;122:669-78.

15 Churg A. Asbestos fibres and pleural plaques in a general autopsy population. Am J Pathol 1982;109:88-96.

16 Wagner JC, Moncrieff CB, Coles R, Griffiths DM, Munday DE. Correlation between fibre content of the lungs and disease in naval dockyard workers. Br J Ind Med 1986;43:391-5.

17 Wagner JC, Pooley FD, Berry G, et al. A pathological and mineralogical study of asbestos-related deaths in the United Kingdom in 1977. Ann Occup Hyg 1982;26:423-31.

18 Gibbs AR. Industrial lung disease. Recent advances in histopathology. Edinburgh: Churchill Livingstone, 1987:109-28.

19 Pooley FD, Wagner JC. The significance of the selective retention of mineral dusts. In: Dodgson J, McCallum RI, Bailey MR, Fisher DR, eds. Inhaled Particles VI. Oxford: Pergamon Press, 1988:187-94

20 Sebastien P, Janson X, Gaudichet A, Hirsch A, Bignon J. Asbestos retention in human respiratory tissue: comparative measurements in lung parenchyma and in parietal pleura. In: Wagner JC, ed. Biological effects of mineral fibres. Lyon: International Agency for Research on Cancer, 1980:237-46. (Sci publ No 30.)

21 Churg A. Accumulation of long asbestos fibres in the peripheral upper lobe in cases of malignant mesothelioma. Am J Ind Med 1987;11:563-9.

22 Churg A, Wood P. Observations on the distribution of asbestos fibres in human lungs. Environ Res 1983;31:374-80.

23 Morgan A, Holmes A. The distribution and characteristics of asbestos fibres in the lungs of Finnish anthophyllite mine workers. Br J Ind Med 1984;33:62-75.

24 Wright $G W$, Kuschner $M$. The influence of varying lengths of glass and asbestos fibre on tissue responses in guinea pigs. In: Walton WH, ed. Inhaled particles IV. Oxford: Pergamon Press, 1977:455-74.

25 Stanton MF, Layard M, Tegeris A, et al. Relation of particle dimension to carcinogenicity in amphibole asbestoses and other fibrous minerals. J Nat Cancer Inst 1981;67:965-75.

26 Lee KP, Kelly DP, Kennedy GL Jr. Pulmonary response to inhaled Kevlar aramid synthetic fibres in rats. Toxicol Appl Pharmacol 1983;71:242-53.

27 Lee KP. Lung responses to particulates with emphasis on 
asbestos and other fibrous dusts. CRC Crit Rev Toxicol 1985;14:33-6.

28 Morgan A, Holmes A. Concentrations and dimensions of coated and uncoated fibres in the human lung. $\mathrm{Br} J$ Ind Med 1980;37:25-32.

29 Timbrell V. Deposition and retention of fibres in the human lung. Ann Occup Hyg 1982;26:347-68.

30 Morgan A, Talbot RJ, Holmes A. Significance of fibre length in the clearance of asbestos from the lung. $B r J$ Ind Med $1978 ; 35: 146-53$.

31 Davies JMG. The pathology of asbestos related disease. Thorax 1984;39:801-8.
$32 \mathrm{McDonald}$ JC, McDonald AD. Epidemiology of asbestos related lung cancer. In: Ahlman K, Aisner J, eds. Asbestos related malignancy. Orlando, Fl: Grune and Stratton, 1987:57-79.

33 McDonald AD, McDonald JC. Epidemiology of malignan mesotheliomas. In: Ahlman K, Aisner J, eds. Asbestos related malignancy. Orlando, Fl: Grune and Stratton, 1987:31-56.

34 Gibbs AR. Role of asbestos and other fibres in the development of diffuse malignant mesothelioma. Thorax 1990;45:649-54.

Accepted 4 March 1991

\section{Destruction of manuscripts}

From 1 July 1985 articles submitted for publication will not be returned. Authors whose papers are rejected will be advised of the decision and the manuscripts will be kept under security for three months to deal with any inquiries and then destroyed. 